\title{
LA GUERRA DEL CHACO EN PERSPECTIVA INDÍGENA: CHAMANES Y NO-HUMANOS EN EL CAMPO DE BATALLA. UNA APROXIMACIÓN A LAS MEMORIAS QOM EN TORNO AL CONFLICTO
}

\author{
The Chaco war in indigenous perspective: shamans and non-humans in the \\ battlefield. An approach to the qom memories about the conflict
}

Agustina de Chazal*

\section{Resumen}

La Guerra del Chaco entre Paraguay y Bolivia (1932-1935) si bien fue un conflicto internacional, dentro del Chaco Boreal ofició como una guerra de ocupación. Invisibilizada por largo tiempo, la situación indígena al momento de la contienda afloró en los últimos años en trabajos que problematizan los abordajes historiográficos sobre la guerra. Este artículo analiza las memorias qom de la Guerra del Chaco enfatizando la participación de los chamanes y las personas no-humanas en la misma. Las narrativas que los qom presentan permiten adentrarnos en una guerra en la que los poderes chamánicos proveyeron subsistencia a los soldados paraguayos, derribaron aviones bolivianos e hicieron que sus armas no funcionasen. Lo presentado constata así la situación qom al momento de la guerra e informa sobre maneras de hacer política y construir historia en conjunto con el cosmos. Asimismo, permite comparar la experiencia de la guerra de grupos qom que habitan tanto en Paraguay como en Argentina.

$<$ Guerra del Chaco $><$ Regímenes de historicidad $><$ Chamanismo $><$ Toba $>$

\begin{abstract}
Although the Chaco war between Paraguay and Bolivia (1932-1935) was an international conflict, at the core of the boreal Chaco area it was a war of occupation. Invisible for a long time, the indigenous situation at the moment of the conflict has recently surfaced in papers that problematize the historiographic approaches of the war. This paper analyses the Qom memories about the Chaco war emphasizing the participation of shamans and non-human beings. The narratives presented by the Qom People allow us to go in depth into a war in which shamanic powers provided subsistence to Paraguayan soldiers, tore down Bolivian planes and made their weapons not to work. This analysis shows the Qom situation at the moment of the war, informs about ways of making politics and history all together with the cosmos, and allows the comparison between the war experiences of Qom communities that nowadays inhabit Paraguay as well as Argentina.
\end{abstract}

$<$ Chaco War $><$ Regimes of historicity $><$ Shamanism $><$ Toba People $>$

Recibido: 01/02/2017 // Aceptado: 27/03/2017

* Estudiante de la Lic. en Ciencias Antropológicas, Facultad de Filosofía y Letras, Universidad de Buenos Aires.tinadechazal@gmail.com 


\section{Introducción}

La temática abordada en este trabajo surge de los relatos y memorias en torno a la Guerra del Chaco de un grupo qom que habita en Villa del Rosario, departamento de San Pedro, Paraguay (comunidad Bagia ga loge lacheg - aldeas Palma y Boquerón) recolectadas durante una estadía de campo de dos meses llevada a cabo en el marco de la realización de mi tesis de licenciatura. Durante la estadía, numerosos miembros de la comunidad y familias enteras mostraron un enorme interés en aclarar y recalcar repetidas veces la participación de sus padres y abuelos en el conflicto bélico, ya sea como baqueanos de los militares o los mismos chamanes y líderes combatiendo al lado del ejército contra la avanzada boliviana.

La presencia estatal del Paraguay en el Chaco Boreal se consolidó a principios del siglo XX cuando logró la conquista de dichas tierras al vencer a Bolivia en la Guerra del Chaco (1932-1935). La soberanía territorial sobre el hoy llamado Chaco paraguayo implicó al mismo tiempo la incorporación de la población indígena al marco estatal: un amplio espacio regional fue finalmente colonizado. Si bien el Estado paraguayo inicia su formación en 1811, fue recién en 1935 que logró efectivizar su presencia en la geografía que se encuentra más allá de la margen oriental del río Paraguay. En este contexto, la Guerra del Chaco fue un conflicto de corte internacional pero que al mismo tiempo operó como campaña de ocupación. La contienda desatada entre Paraguay y Bolivia en el Chaco Boreal efectivizó y finalizó un largo proceso de conquista iniciado siglos atrás con la colonia y las avanzadas republicanas del siglo XIX. Fue la presencia de los ejércitos paraguayos y bolivianos a principios del siglo XX la que desembocó en "la tardía colonización de estas tierras" (Capdevila et al., 2010: 2). Así como la conquista y colonización del Chaco argentino comenzó a gestarse hacia fines del siglo XIX con las campañas de Bejamín Victorica y culminaron con la campaña militar de ocupación en 1911 a raíz de la cual los indígenas de la zona debieron asentarse en distintas reducciones (Iñigo Carrera, 1983); estos procesos estatales de ocupación y colonización no se efectivizarían en el Paraguay hasta entrado el siglo XX.

El lugar central que tiene la Guerra del Chaco en la memoria y los relatos históricos de los pueblos del Chaco paraguayo es entendible si contemplamos que dicho conflicto no fue ajeno a la población indígena, sino todo lo contrario. Los ejércitos arribaron a territorio chaqueño e instalaron sus fortines militares en las cercanías de los asentamientos indígenas. En este marco, presentada por la historiografía paraguaya como una guerra de un Estado frente a otro, la situación indígena durante el conflicto fue completamente borrada. Fueron los trabajos antropológicos publicados a mediados de los años 2000 los encargados de discutir los relatos oficiales y visibilizar la realidad indígena al momento de la guerra, sus memorias y las distintas maneras en que los pueblos del Chaco paraguayo se vieron involucrados y avasallados (Richard, 2008; Capdevila et al., 2010; Capdevila, 2011, 2013, 2015).

Teniendo como guía la propuesta de dichos autores y la problemática de la invisibilización de la situación y participación indígena durante el conflicto, en lo que sigue recuperaremos las memorias sobre la Guerra del Chaco del grupo qom "rosarino" 
(denominados así por residir en el distrito de Villa del Rosario) con el objetivo de visibilizar las maneras en que se involucraron en el conflicto bélico y cómo el quehacer político no-humano actuó durante el mismo. Las narrativas recabadas dan cuenta de la contemporaneidad de la problemática para la comunidad, del reclamo actual y la necesidad de revalidación de la participación de sus parientes en el conflicto. Al mismo tiempo, muestran un régimen de historicidad en el que la guerra aparece como un marcador de la pérdida territorial y construyen un conflicto en el que para que el Paraguay resulte vencedor fue necesario el accionar chamánico.

A modo de introducción, en una primera instancia realizaremos un breve recorrido por la contienda para luego adentrarnos en la participación indígena en la misma. Dado que nos informan sobre el accionar de los chamanes durante el conflicto, retomaremos particularmente las experiencias ishir, angaité y enlhet para ponerlas en diálogo con aquellas qom rosarinas. Indagaremos en las memorias y los relatos poniendo especial énfasis en los roles de chamanes y líderes como baqueanos. Esto permitirá plantear que las maneras chamánicas de participación en la Guerra del Chaco son una forma de hacer política en conjunto con personas no-humanas ${ }^{1}$. Asimismo, el abordaje de las memorias del grupo en cuestión permitirá preguntarnos por la experiencia del conflicto de parcialidades de un mismo pueblo indígena en dos marcos estatales distintos, abordando así las diversas representaciones en torno a la contienda. En este contexto, realizaremos una acotada aproximación comparativa entre las memorias de la Guerra del Chaco de grupos toba tanto del Paraguay como de Argentina.

\section{Contextualización geográfica: los qom en el Paraguay}

La idiosincrasia nómade y guerrera de los grupos toba es ampliamente conocida (Kersten, 1968 [1904]; Susnik, 1981, 1986-87; Métraux, 1963). La misma implica un constante movimiento a través de un amplio territorio en búsqueda de presas así como de scalps (cf. Métraux, 1963; Nordenskiold, 1912; Arnott, 1934). Acorde a ello, Susnik (1981) da cuenta que a mediados del siglo XVIII los toba incursionaban sobre la margen oriental del río Paraguay. La autora llama a estos grupos "ntokowit-tobas" (Susnik, 1981, 1986-87) y, siguiendo las previas divisiones mencionadas por Métraux (1963), los subdivide en tres grupos regionales según sus "áreas de cazadero más estables" (Susnik, 1981: 35): el grupo "komlek ocupaba las tierras del alto R. Pilcomayo (...) tenían al norte por sus vecinos a los Chiriguano-Guaraníes y en el sur y suroeste a los Mataco" (Susnik, 1981: 35). Los "takshik" (luego considerados formoseños) ubicados en "la junta del R. Teuco con el R. Bermejo hacia el R. Pilcomayo inferior" (Susnik: 1986-87:30). Y un "grupo central” ubicado "entre el medio R. Bermejo y el medio R. Pilcomayo" (Susnik, 1981: 35), definidos por la autora como "amigos de los Mocovíes y de los Pilagás" (Susnik, 1986-87: 30). La etnógrafa eslovena informa que tanto los takshik como el grupo central incursionaron sobre la zona oriental del río Paraguay, los primeros "desde la confluencia del Pilcomayo al sur" mientras que los segundos desde

Sobre la noción qom de persona no-humana $c f$. Tola (2012). Sobre los no-humanos, la política y la Guerra cf. Tola y Suárez (2016). 
la zona media del Pilcomayo cruzándolo hacia el norte (Susnik, 1981: 36). La autora da cuenta que en la segunda mitad del siglo XVIII este grupo toba se movilizó "desde la zona del Estero Patiño (...) hacia las cabeceras del R. Confuso" (Susnik, 1986-87: 30) y que al ocupar las tierras al norte del Pilcomayo consiguieron también la periferia de las riberas del río Paraguay (Susnik, 1981, 1986-87). Según Susnik, este grupo toba solía llamarse "toba-mirí" en contraste con los "toba-guasú" del Pilcomayo sur (Susnik, 1981, 1986-87).

Para finales del siglo XIX, Susnik $(1981,1986-87)$ ubica a los toba teniendo de vecinos a grupos lengua. Es en esta época que se produjo la denominada fusión tobamaskoy (Susnik 1981, 1986-87; Zanardini, 2011). Las informaciones muestran que el vínculo tuvo lugar luego de que en una expedición punitiva realizada por el gobierno paraguayo la población toba fuera diezmada (Susnik, 1981, 1986-87; Zanardini, 2011). En este contexto, los toba se habrían unido con grupos maskoy a través del matrimonio mixto (Susnik, 1981, 1986-87; Zanardini, 2011). A partir de este hecho, Susnik (1981, 1986-87) propone que se produciría una subdivisión en tres parcialidades o cacicatos siguiendo los nombres de tres líderes. Uno de ellos habría sido el grupo del cacique "Lowogaik, de origen toba puro, pero su grupo habiendo integrado potencialmente a las mujeres maskoy, fundando su propia "colonia" agrícola en Rosario. En la segunda generación la lengua toba iba imponiéndose, si bien conservaron algunos vocablos maskoy referentes a las actividades propias de mujeres" (Susnik, 1986-87: 31).

Susnik plantea que el líder Lowokaik era de puro origen "kom-lïk" (Susnik, 1981: 49) y que la influencia maskoy en dichos grupos qom se transluciría en "su lucha por la reorientación económica tendiente a la agricultura” (Susnik, 1981: 49). Por su lado, Zanardini aclara que cuando los "qom-lik" llegaron al río Confuso "se autodenominaron emok-lik, que significa los habitantes de la ribera izquierda (del río)" (Zanardini, 2011: 145) y que debemos recordar que "existen grupos de estos indígenas que migraron desde el sur del Chaco hasta el Alto Paraguay, "maskoyzándose", es decir fusionándose con los de la etnia Maskoy" (Zanardini, 2011: 146). Resulta interesante destacar la aclaración señalada por Fabre (2006) al plantear que "El nombre Emok (-toba) no debe confundirse con el Toba (-maskoy) enenlhet (familia enlhet-enenlhet). Emok (-toba) es un gentilicio usado solamente en el Paraguay. Es de origen enlhet, lengua en la que significa 'prójimo, paisano' (Fabre, 2006: 94). De esta manera, cuando los grupos toba qom del Chaco paraguayo son referidos como emok no deben considerarse maskoy sino que, siguiendo a Fabre, fueron denominados de dicha forma por sus vecinos históricos en el Paraguay: los grupos lengua o enlhet. Hoy día los toba-maskoy o enenlhet son ampliamente conocidos y habitantes de la zona de Puerto Casado en el Paraguay. Sin embargo, no son los toba qom que efectivamente habitan en Villa del Rosario y en Cerrito.

Para el comienzo de la Guerra del Chaco, los qom rosarinos se encontraban en la ribera del río Paraguay frente a la ciudad de Rosario ${ }^{2}$. Esta información coincide con

\footnotetext{
2 "El asentamiento principal de los qom rosarinos se encontraba frente a la ciudad Rosario, en el lugar
} denominado hoy Pto. Carlos Pfannl, ex Pto. 25". En: "Breve historia de la comunidad qom "Baialougue". 
los relatos de los ancianos y especialmente con los datos de la cédula de identidad de un anciano ya fallecido a la que tuvimos acceso a través de su nieta. La cédula contiene el nombre y apellido de la persona, una foto 4x4 y declara: "Nació el 8-1-1931 en Pto. 25 - Chaco. Profesión: agricultor". El período de guerra se vuelve invisible en las páginas dedicadas a la parcialidad (Zanardini, 2011; Chase-Sardi, 1971) ya que se retoma la ubicación del grupo para 1950. Sin embargo, a través de los trabajos de relevamiento realizados dentro del Proyecto de Desarrollo Rural Sostenible (PRODERS) del Ministerio de Ganadería y Agricultura ${ }^{3}$ sabemos que el grupo habría permanecido en las inmediaciones de Puerto 25 sobre la margen occidental del río Paraguay hasta los años 40 .

\section{Tobas de acá y de allá}

Durante la estadía de trabajo de campo, el vocablo "pilagá" se hizo presente en los relatos de un anciano de la comunidad así como en el reconocimiento del origen pilagá de su abuelo por parte de un chamán y antiguo líder. Al mismo tiempo, entre los qom rosarinos está presente la figura de Ashen cuyo relato comparte -con variacionespuntos en común con los de la figura de Asin entre los toba y pilagá recolectados por Métraux (1946) y por Gordillo (2005). Al sumar estos indicios a las migraciones toba desde el Estero Patiño y el Pilcomayo medio hacia el río Confuso y el río Paraguay, podría pensarse, intercambio o no con grupos lengua de por medio, a los toba rosarinos como un posible desprendimiento de gente toba del Pilcomayo medio. Siguiendo esta geografía, en el área cercana al antiguo cauce del río Pilcomayo y los bañados generados por la retirada del mismo, actualmente habitan los llamados "tobas del oeste" a veces también denominados toba-pilagá (Gordillo y Leguizamón, 2002; Gordillo, 2010b; Córdoba y Braunstein, 2008). Estos grupos recorrían las tierras ancestrales ubicadas a ambas orillas del Pilcomayo medio, denominadas "la banda" (Gordillo, 2005, 2010a, 2010b; Córdoba y Braunstein, 2008; Córdoba, 2016). Gordillo plantea que los lugares se construyeron bajo la noción de "la banda" como resultado de la instauración de la frontera internacional sobre el río en cuestión "ya que en el pasado las bandas tobas usaban ambas márgenes del río y no consideraban al ñachi (el río) como un límite entre territorios diferentes" (Gordillo, 2010b: 68). Inclusive una vez finalizada la Guerra del Chaco los grupos toba y pilagá continuaban cruzando el río hacia Paraguay para cazar, recolectar o pescar (Gordillo y Leguizamón, 2002; Córdoba y Braunstein, 2008). La persistencia en alcanzar las tierras hoy consideradas "paraguayas" da cuenta todavía a mediados del siglo XX del antiguo patrón de movilidad toba que abarcaba

Anexo en documento legal realizado, firmado y presentado por Servicios Profesionales SocioAntropológicos y Jurídicos frente al Instituto Paraguayo del Indígena el 25 de abril de 1988, Asunción.

PRODERS es un proyecto del Gobierno Nacional destinado a incidir en la calidad de vida de pequeños productores rurales y comunidades indígenas. En lo concreto de la comunidad en cuestión, PRODERS realizó trabajos de relevamiento habitacional, de subsistencia e infraestructura de las aldeas, participó de la -precaria- instalación eléctrica y la construcción del pozo de agua. También distribuyó semillas y elementos para la producción agropecuaria de baja densidad para el propio consumo de cada unidad habitacional. 
un inmenso territorio ahora sesgado, fragmentado y modificado por la presencia de los ejércitos nacionales y la instauración de una frontera "sobre un río que aún estaba bajo control indígena” (Gordillo y Leguizamón, 2002: 23). En este contexto geográfico, tal como argumentan Córdoba y Braunstein (2008), la Guerra del Chaco y la instauración de la frontera internacional sobre el río modificaron los patrones de asentamiento y desplazamiento de los grupos del Pilcomayo medio.

Si bien ningún vínculo directo entre poblaciones qom actuales de Paraguay y Argentina puede ser establecido con seguridad como tampoco puede establecerse con certeza el origen de los qom de Villa del Rosario, lo que está claro es que los grupos toba se han movido por Argentina y Paraguay mucho antes de que estos países existan como tales y supieron ser una "tribu tan nómade y errante cuyos límites tribales antiguos no podría establecerse si no fuera que se nos ofrece la oportunidad de hacerlo a partir de la situación actual" (Kersten 1968[1904]: 60). A principios del siglo XX fue Kersten quien ubicó a los toba viviendo "en número considerable, sobre ambas márgenes del Pilcomayo, extendiéndose profundamente hasta el Chaco Boreal" (Kersten 1968[1904]: 60). Más de cien años después, no estamos en condiciones de seguir su propuesta de establecer los límites tribales antiguos a partir de la ubicación actual sino simplemente sugerir posibles vínculos entre grupos toba de Argentina y Paraguay con base a la información disponible.

\section{Actuales ubicaciones qom en Paraguay}

La mayor concentración de población se encuentra en las comunidades de Cerrito, bajo Chaco paraguayo, donde se subdivide en tres grandes grupos: los cerriteños, los chaqueños y los rosarinos. Los cerriteños son el grupo mayoritario y se llaman así por ser los originarios o los primeros en haber llegado a Cerrito. Los chaqueños, autodenominados de esta forma por provenir del Chaco, viven a aproximadamente dos kilómetros de distancia a la altura del peaje de Río Verde. Y por último, los rosarinos. El grupo rosarino que hoy día vive en Cerrito es originario de Villa del Rosario, distrito localizado a unos 250 kilómetros de Asunción. Allí se encuentra la comunidad Bagia ga loge lacheg, dicho nombre significa "Gente del Río" o "Ribereños": independientemente de su locación actual a pocos kilómetros del río Paraguay, esta parcialidad qom se reconoce a sí misma como históricamente habitantes de tierras ribereñas. Entre los rosarinos de Cerrito y la comunidad de Villa del Rosario fue donde se llevaron a cabo las estancias de campo y donde se recolectaron las memorias.

\section{La ocupación del Chaco Boreal, la Guerra del Chaco (1932-1935)}

La presencia itinerante y aislada de los estados en el Chaco Boreal, la ocupación sectaria de los capitales nacionales y extranjeros y los recorridos de misioneros religiosos conformaron una geografía imbricada de a bloques con caminos que se abrían entre territorios indígenas. El mapa del Chaco hacia 1930 aparece así como una cartografía del desorden (Comaroff y Comaroff, 2009), como un espacio regional en el que "el 
alcance del Estado es desigual y el paisaje un palimpsesto de soberanías contestadas" (Comaroff y Comaroff, 2009: 17). Extractores de tanino, religiosos, agentes militares, empresarios, líderes y comunidades indígenas, seguridad privada de las empresas, latifundistas y estancieros se disputaban la ocupación territorial de diferentes maneras. En esta geografía se desarrolló el conflicto bélico impulsado "por la ausencia de una delimitación clara en la época colonial respecto a la administración y titularidad del Chaco, ambigüedad heredada por los Estados paraguayo y boliviano, quienes a su vez tuvieron motivaciones propias para concurrir a la disputa" (Villagra, 2014: 30). Si bien a principios del siglo XIX la República del Paraguay declaró para sí misma la titularidad y propiedad sobre el Chaco a través del Acto de Gobierno de 1825 (Villagra, 2014), estos no fueron más que actos "virtuales" ya que "no existía posesión efectiva de las tierras por parte del Estado" (Villagra, 2014: 27). La potestad y efectiva "posesión" sobre el Chaco no se concretaría hasta finalizado el conflicto en 1935 y es recién en 1945 que la región "se incorpora a la administración territorial, aunque con el status de territorio militar” (Vázquez, 2012: 160).

Previo al avance militar, una serie de conferencias diplomáticas intentaron resolver las demandas de ambos países. Sin embargo, las mismas fracasaron debido a las presiones de las petroleras multinacionales que buscaban desarrollar su actividad en la zona: la Standard Oil se manifestó a favor de Bolivia y Shell de Paraguay (Villagra, 2014). Agotada la vía diplomática, ambos países comenzaron con los avances militares sobre el terreno. Desde el extremo norte descendiendo hacia el sur, Bolivia instaló sus puestos militares y fortines a lo largo del río Pilcomayo (Villagra, 2014). Por su lado, Paraguay exploró y ocupó el Chaco desde las orillas del río Paraguay ${ }^{4}$.

No es el objetivo de este trabajo realizar una cronología detallada sobre el desarrollo del conflicto sino abarcar al mismo más allá de la disputa entre dos países enemistados por la soberanía nacional sobre un amplio territorio. Siguiendo la propuesta de Villagra (2014) y Capdevila et al. (2010), el objetivo aquí es pensar a la Guerra del Chaco como una campaña de ocupación de los territorios indígenas. En este sentido, es importante destacar que la estrategia paraguaya consistió en penetrar en el Chaco de la mano de baqueanos indígenas que guiaban y acompañaban a generales y militares: el avance militar se realizó siguiendo las "líneas de fuerza que organizaban el Chaco indígena" (Richard, 2008: 23). Los fortines militares ${ }^{5}$ se establecieron sobre asentamientos indígenas y las poblaciones nativas fueron masivamente desplazadas: "la geografía militar calcó la geopolítica india" (Richard, 2008: 23). Se abrieron redes de caminos y se establecieron campos de operaciones, se formaron milicias indígenas

\footnotetext{
${ }^{4}$ Sobre la guerra desde la historiografía boliviana ver Querejazu Calvo $(1975,1990)$.

5 "Los fortines, bien o mal llamados con ese nombre, estaban constituidos por grupos de soldados con o sin oficiales, cobijados bajos rústicos techos y fusil en mano, con misión de custodiar la transitoria línea de frontera amagada constantemente por el adversario" (Testimonio del Mayor Sindulfo Barreto en Bejarano, 1984: 69). Instalados en el corazón del Chaco, los fortines militares se caracterizaron por la precariedad y la escasez de recursos dada la dificultad del transporte y la comunicación a través de los pequeños caminos internos. Varios fortines estaban rodeados con un perímetro de trincheras. Sobre la vida en los fortines, ver Bejarano (1984).
} 
y se relocalizaron aldeas completas en misiones y reservas (Richard, 2008). La guerra modificó completamente el paisaje habitado por poblaciones y comunidades que a partir de este momento dejaron de poseer de facto los territorios que ancestralmente habitaron.

Las tropas paraguayas que llegaron al Chaco durante la guerra se instalaron a vivir allí por largos meses: lentamente se formaron plazas militares, se trazaron nuevas rutas y se establecieron puestos de abastecimiento (Capdevila, 2010). Para 1932, desde el gobierno de Asunción surgió un proyecto de ley con la intención de transformar a los combatientes en colonos: "Se atribuían parcelas de 200 hectáreas, calificadas como "patrióticas", a los oficiales, y lotes de 60 hectáreas a los soldados y cabos beneméritos" (Capdevila, 2010: 22-23). Una vez finalizada la guerra en 1935, algunas tropas permanecieron en el terreno estableciendo de esta manera el control permanente tanto de las tierras como de los pobladores chaqueños. Éstos se incorporaban a un marco estatal que los recibía como "ciudadanos" al mismo tiempo que los dejaba errantes sin tierras para habitar. La colonización y ocupación del Chaco a través de la guerra contra Bolivia significó, finalmente, "un modo militarizado de dominación y relacionamiento del Estado con los pueblos indígenas" (Villagra, 2014: 31).

En los años posteriores, el atropello continuó en un marco gubernamental (Foucault, 1991) que tuvo a los actores privados como primera herramienta. Así como en el siglo previo los capitales privados y los religiosos fueron la presencia no indígena en zona chaqueña, finalizado el conflicto nuevos actores entraron en escena: el Estado paraguayo dejó "la administración del Chaco (y entonces la gestión de las relaciones con los indígenas) a los actores privados del frente pionero: misioneros, estancieros, madereros" (Capdevila, 2010: 119). El ejército se retiró dejando soldados que "vigilaban la "frontera", protegiendo a los colonos de los ladrones de ganado y, todavía en los años 1960, disparaban a los "indios salvajes" aislados cuando salían del monte" (Capdevila, 2010: 119).

Las consecuencias de la guerra y el impacto del gobierno paraguayo que se implementaba en la zona fueron de amplio espectro: indígenas replegados, reagrupados, dispersos y mezclados entre las estancias y empresas que se establecieron sobre sus tierras, modificación de nombres propios a nombres no indígenas (tanto de lugares como de personas), introducción del ganado, reducción de la movilidad, aumento del consumo de bienes no indígenas, introducción al guaraní y gradual pérdida de lenguas propias (Villagra, 2014). Una de las principales consecuencias fue la desterritorialización: no sólo fueron despojados de sus territorios, finalizada la guerra las promesas de tierras en retribución a la colaboración brindada al ejército no fueron más que palabras vacías que nunca llegaron a concretarse. La posterior invisibilización de la participación indígena en el conflicto no fue de ayuda alguna para los futuros reclamos.

\section{El Chaco indígena en la guerra}

La participación indígena en la Guerra del Chaco hoy día está ampliamente reconocida y documentada (Richard, 2008; Richard et al., 2007; Capdevila et al., 2010). En primer lugar, su presencia se hace notable a través de los relatos de exploradores y militares como Juan Belaieff (Richard, 2008) y Ángel Ayorea (Combès, 2010). Belaieff 
es reconocido por haberse adentrado en el Chaco Boreal a través de la Bahía Negra en el Alto Paraguay los años previos a la guerra y por haber establecido importantes vínculos con caciques y miembros de comunidades chamacoco y maká que le oficiaron de baqueanos. En segundo lugar, la situación indígena al momento de la guerra y su perspectiva del conflicto es conocida a través del trabajo etnográfico realizado por varios antropólogos que recolectaron las memorias de grupos nivaclé (Barbosa y Richard, 2010), angaité (Villagra, 2014), ishir (Cordeu, 2008) y problematizaron la situación de grupos enlhet (Kalish y Unruh, 2008), ayoreo (Combès, 2010), chané e isoseños (Bossert et al., 2008) y de los grupos del Pilcomayo medio (Córdoba y Braunstein, 2008; Córdoba, 2016). No se explicitará aquí la experiencia del conflicto de cada uno de estos grupos sino que se planteará el panorama general para adentrarnos en la participación qom en la guerra en cuestión a través de las memorias recolectadas durante la estadía de campo.

Es innegable el impacto que tuvo la guerra sobre los pueblos del Chaco dado que los grupos militares se instalaron sobre las zonas de asentamiento indígenas, utilizaron sus recursos de subsistencia y mano de obra forzada para la apertura y construcción de caminos y trincheras, como en el caso enlhet (Kalisch y Unruh, 2008). Estas alianzas con grupos indígenas fueron resultado de la iniciativa de los militares en el terreno (Capdevila, 2010). Fue clave para la victoria paraguaya el aprovechamiento del conocimiento del territorio chaqueño que poseían los indígenas y la formación de milicias con miembros de las comunidades de la zona que fueron armados para el combate (Córdoba y Braunstein, 2008). El impacto de la guerra sobre los pueblos fue masivo: muchos quedaron en el fuego cruzado (nivaclé), algunos fueron reclutados como "voluntarios" y guías (maká y enxet) mientras otros abandonaron sus tierras para alejarse y sobrevivir (Villagra, 2014). Otros tantos fueron "simplemente masacrados por ambas partes del conflicto" (Villagra, 2014: 31). Estas formas de violencia ejercidas contra los indígenas, sin embargo, no estaban destinadas a un "enemigo" (Kalisch y Unruh, 2008) sino a obtener los recursos necesarios para alcanzar la victoria. En este contexto, Capdevila da cuenta de las "variaciones de los sentimientos de violencia según los territorios" (Capdevila, 2011: 4) y plantea que las experiencias indígenas de la guerra difieren en sus cronologías ya que éstas sobrepasan el momento exacto de la guerra. Las narraciones indígenas se inscriben así en una larga temporalidad que no conlleva una cronología lineal (Capdevila y Richard, 2016). Los autores argumentan que no se trata de narraciones estructuradas ni colectivas ya que combinan la experiencia particular de cada grupo (y cada narrador) con el conflicto que se desenvolvió sobre sus territorios: las memorias indígenas sobre la Guerra del Chaco corresponden a "regímenes de historicidad híbridos" (Capdevila y Richard, 2016: 5, traducción nuestra). Al interior del Chaco paraguayo las variaciones en las maneras de vincularse con la guerra son notables (Capdevila, 2013; Rabinovich et al. 2015): los grupos del Pilcomayo medio evitaron los ejércitos replegándose, los enlhet y angaité adoptaron una estrategia más bien sumisa, los maká y nivaclé se vincularon directamente con los militares y se sumaron al combate, y otros grupos se hicieron eco del conflicto para guerrear con sus enemigos tradicionales (Rabinovich et al. 2015). En este marco, Córdoba y Braunstein 
(2008) muestran que Métraux (1933) al momento del conflicto se preguntó sobre la posibilidad de que la guerra entre Paraguay y Bolivia operase al mismo tiempo como una continuidad con las guerras tradicionales de los grupos indígenas del Pilcomayo. Tal es el caso para los toba-pilagá, quienes al cruzar el río Pilcomayo para pescar se hicieron de pertrechos de guerra abandonados por los ejércitos "que luego utilizaron contra sus enemigos tradicionales" (Córdoba y Braunstein, 2008: 143).

Una de las conocidas y recordadas formas de participación indígena en la Guerra del Chaco fue a través del conocimiento y las habilidades de los chamanes (Cordeu, 2008; Fritz, 2008; Villagra, 2014). Ellos fueron baqueanos y gracias a su accionar la armada paraguaya contó con una gran ventaja: las armas enemigas no funcionaron, aviones fueron derribados y aguadas y recursos de subsistencia fueron encontrados en el corazón del Chaco paraguayo donde la escasez de recursos era tan problemática como la presencia del enemigo. Dicha participación se hace presente especialmente en las memorias ishir recolectadas por Cordeu (2008) donde se destacan las habilidades de baqueano y rastreador de un antiguo chamán "quién portaba en su equipaje sus implementos mágicos" (Cordeu, 2008: 264) y cuyas "revelaciones" recibidas durante la guerra "le permitieron [...] el descubrimiento de una aguada desconocida; pudiendo salvar así a 400 paraguayos próximos a perecer de sed" (Cordeu, 2008: 265).

Para el caso angaité, también Villagra (2014) da cuenta del accionar chamánico durante la guerra, particularmente de un chamán que "ingiriendo pólvora domina al señor de la misma y se salva de las balas" (Villagra, 2014: 114). AAntonio Ka'a, chamán combatiente angaité, "las balas le pasaban por el costado, él usaba sus poderes internos, él probó la pólvora y eso le salvó" (Simón Duarte en Villagra, 2014: 101).

En la variedad de experiencias de la guerra atravesadas por los pueblos del Chaco paraguayo los relatos no sólo dan cuenta del rol oficiado por los chamanes en el combate como parte de la avanzada del Paraguay, sino que también constatan la violencia ejercida contra los indígenas. Tal es el caso enlhet, entre quienes el conocimiento tradicional de los ancianos y chamanes fue utilizado para defenderse de los atropellos de los militares, "[...] los ancianos sabían hacer que el arma de fuego no detonara; que los soldados perdieran inesperadamente su furia, que comenzaran incluso a temblar de miedo. Los ancianos hacían caer aviones; hasta hacían que hombres que intentaban violar a mujeres no pudieran cumplir con sus deseos, porque de repente los dejaban impotentes" (Kalisch y Unruh, 2008: 105).

En concordancia con las experiencias ishir, angaité y enlhet, a continuación presentaremos las memorias qom de la guerra que destacan la participación de un grupo de chamanes y antiguos líderes de la comunidad. Estos relatos buscan enfatizar tres cuestiones principalmente: que el Paraguay venció en la guerra gracias a los indígenas, que fueron los chamanes los encargados de que las armas enemigas no funcionaran y que los aviones no llegaran a destino y que la participación qom no fue reconocida ni indemnizada correctamente.

${ }^{6}$ Sobre la estadía de Métraux entre grupos toba-pilagá y su artículo en torno a la guerra indígena publicado en 1933, ver específicamente Córdoba (2016). 


\section{Chamanes qom en el campo de batalla}

Si hay algo en lo que coinciden los miembros de la comunidad sobre la Guerra del Chaco es en que los paraguayos hasta el día de hoy no reconocen que ganaron la contienda gracias a la participación de líderes y chamanes indígenas. Una de las principales consecuencias de tal invisibilización fue la pérdida de tierras o, en otras palabras, el acceso denegado a tierras prometidas durante la guerra a modo de agradecimiento.

Las memorias qom sobre la guerra muestran que se involucraron en el conflicto bajo dos aristas. Por un lado, líderes que guiaron las tropas paraguayas por las vastas áreas del Chaco Boreal. Por el otro, los mismos líderes operaron también "a distancia" con sus poderes y conocimientos chamánicos. En aquel entonces, existían dos tipos de líderes. Uno, el "cacique de paz" y otro, el "cacique de guerra". Ambos, para ser "caciques" debían ser también chamanes. Cada uno cumplía un rol particular en la tarea de liderar a la comunidad. El cacique de paz era el que se quedaba en la comunidad en época de conflictos. Su rol era defender al grupo, comunicarse con sus "socios" nohumanos para saber qué se avecinaba, si una enfermedad, una peste o un ataque. El cacique de paz era el encargado de informar a la comunidad qué debía hacerse.

Por otro lado, el cacique de guerra era quien salía de la comunidad. En el caso que nos ocupa, fue quien acompañó al ejército paraguayo. Los testimonios relatan que el cacique de guerra ofició de baqueano pero sobre todo salvó a los militares de las vicisitudes que no podían enfrentar por sí solos, proveyó agua, alimentos, subsistencia. En palabras de uno de nuestros interlocutores: "Emilio fue líder, en medio de la guerra de Bolivia con Paraguay era baqueano. Llevaba grupos de soldados hasta donde estaban los bolivianos. Los paraguayos no murieron de sed como los bolivianos porque los indígenas los ayudaron, con un fruto de bajo tierra que tenía líquido en su interior. Karaguata: cuando llovía se acumulaba bajo tierra el líquido" (Yoel, 9/7/2014, Palma) . Los caciques de guerra proveyeron subsistencia a los soldados paraguayos a través de su conocimiento del terreno para encontrar alimento pero también a través del canto chamánico: "Cuando necesitaban agua, ellos cantaban esa noche y llegó ya el agua para defender su tropa... y cantaban... y ahí llovió y salvaron otra vez nuestros compatriotas" (Herculano, 28/07/2014, Boquerón).

Asimismo, a su regreso el cacique de guerra era el encargado de relatar a la comunidad lo sucedido durante la guerra: "Emilio no murió [en la guerra], cuando terminó la guerra volvió a su comunidad y contó lo que hizo, lo que pasó y lo que vio, y por eso nosotros sabemos" (Yoel, 9/7/2014, Palma). La enfatización discursiva del éxito de los caciques de guerra en la contienda con Bolivia al recalcar que ellos no murieron -en contraposición a soldados bolivianos y paraguayos que sí lo hicieron- no sólo da cuenta de las capacidades chamánicas y su alto reconocimiento sino que opera al mismo tiempo como el marcador discursivo que justifica y argumenta el origen del contenido narrado, un conocimiento de primera mano adquirido directamente de aquel chamán que venció y regresó con vida.

7 Los nombres de los interlocutores fueron modificados. Entre paréntesis se aclara fecha y lugar en que se recolectó el testimonio a través de entrevistas y conversaciones informales. 


\section{Derribando aviones y espiando enemigos}

Los qom denominan "socios" a los poderes asociados del chamán. Estos poderes están directamente vinculados a los "dueños" (de los animales, del campo, del monte y del agua), poseen agencia ${ }^{8}$, socialidad y son parte de la corporalidad del chamán (Tola, 2010a, 2012). Los poderes asociados del chamán son los lavanec (cf. Wright, 2008), ellos entran y salen del cuerpo del chamán, viajan por el cielo, participan en el proceso de curación, son enviados a causar enfermedades y también, en el caso de la Guerra del Chaco, a espiar y derribar aviones?.

Tal como relata Salvador, su abuelo chamán guiaba a los soldados y "utilizaba lo que sabía de la naturaleza, porque ya se morían [los paraguayos], el aire usaban, usaban la naturaleza y las armas y los camiones no funcionaban. Cuando venían los aviones, allá lejos vienen, ya se caen, no llegan donde los soldados" (Salvador, 7/8/2014, Palma). De esta manera, el chamán se comunicaba con sus socios no sólo para encontrar recursos de subsistencia sino también para que éstos intercedieran con el armamento del enemigo. El cacique de guerra hizo que los aviones enemigos se cayeran, que las bombas no explotaran y que las armas no disparen o las balas se desvíen: "Si hay un avión que pone bomba, hacían al avión y la bomba bajaba pero no explotaba, y el avión así luego caía y morían todos ellos, pero no los paraguayos, y así no murieron. Así ganaron, porque los indígenas los protegían" (Rosa, 17/8/2014, Palma).

Los socios de los chamanes también fueron espías en la Guerra del Chaco, sondearon el territorio y regresaron con las noticias de qué sucedía entre los enemigos. De igual forma, los socios mantuvieron las vías de comunicación entre el cacique de guerra que se encontraba en el frente de batalla y el cacique de paz que se quedaba en la comunidad:

Los bolivianos hicieron kilómetro por kilómetro el teléfono de los montes para comunicar allá su central para venir [que vengan] otra vez las tropas, refuerzo. Y después entró los indígenas, los chamán. Ahí ellos quedó ya, porque los indígenas, el chamán manda un loro no más su teléfono, él cantó esa noche, mandó allá, cuántos soldados bolivianos está ahí, qué arma, cómo está ahí. Después al otro día vino otra

\footnotetext{
8 Entendida de manera amplia como capacidad de acción, voluntad, intención y conciencia reflexiva.

9 "Socios", "dueños" y lavanec, al igual que la concepción de los poderes del chamán como "seres" o "bichos" que poseen agencia propia y que conforman la corporalidad del chamán, son términos y nociones de los qom rosarinos que surgieron en el trabajo de campo. Dado lo acotado de este artículo no las abordamos desde un análisis de nuestros datos propios. La referencia a la bibliografía escrita sobre grupos toba orientales no intenta aquí hacer una suerte de explicación generalista de los "mecanismos cosmológicos qom" sino situar la temática del chamanismo dentro de este pueblo indígena. Como leemos en las memorias y narrativas transcriptas, fueron estos poderes -enviados por los chamanes- quienes actuaron de diversas maneras en la Guerra del Chaco. Focalizar en el accionar chamánico durante el conflicto bélico apunta a visibilizar las formas de participación y discursividad indígena y a profundizar el análisis de la situación de grupos toba en el conflicto, así como de las diversas representaciones del mismo desde una perspectiva que contemple el accionar bélico y socio-político de los no-humanos y su rol en la construcción de historicidad.
} 
vez el loro, contó TODO, el chamán que hay acá, y cuánto, y cómo. Y después el chamán comunicó su tropa, jefe también, entonces ahí fracasó los bolivianos. Los indígenas chamán no necesita para hacer un teléfono, está a kilómetros eso, manda no más un pájaro, fue ahí, controlo todo, cuánto guardia está, cuánto kilometro está ahí, ahí cayó los bolivianos (Herculano, 28/07/2014, Boquerón).

Dado que de la comunidad qom quienes combatieron fueron los chamanes, las memorias focalizan en cómo su accionar hizo que el Paraguay resulte vencedor. En este marco es que en la narrativa sobre la experiencia de la guerra, hombres y mujeres se acreditan la victoria al recalcar que ellos (como pueblo) fueron a la guerra a defender su territorio. Sobre ello me detendré a continuación.

\section{Ir a la guerra para defender nuestro territorio}

La reivindicación de la participación qom se enraíza en la preexistencia indígena en el territorio del Chaco y en el afán de no perderlo -nuevamente- frente a un extraño (en este caso los bolivianos). Cuando las memorias de la guerra se hacen presentes el porqué de la participación qom se revela distinto al de otros pueblos. No aparecen elementos de violencia física ejercida por el ejército contra los qom sino que ellos manifiestan haber ido a la guerra para defender sus tierras, razón por la cual debieron aliarse con los paraguayos y ayudarlos a vencer:

Los indígenas cuando comienza la guerra [del Chaco] ellos siempre hicieron reunión, hablar a la gente, nuestro compatriota [los paraguayos] está de guerra, parece que los bolivianos quieren nuestro agua también, nuestra tierra, si pierden los paraguayos nosotros vamos a ser cargo de los bolivianos, y después... dos años ya la guerra y va a perder nuestro compatriota... y todo un reunión [se hablaba], tenemos que nosotros ir también para defender nuestra patria... pero solamente los chamanes tienen que ir (Herculano, 28/7/2014, Boquerón).

La noción de "compatriota" aplicada a los paraguayos se desprende del considerar a los mismos como "mestizos", hijos de españoles e indígenas, no originarios de estas tierras. En este marco es que la lógica de defender "nuestras" tierras -que ya estaban siendo expropiadas por los paraguayos- cobra mayor sentido, porque "Paraguayos ya no son originales, son mestizos, de indígenas y español. Los europeos vinieron y no había paraguayos, sólo indígenas" (Manuel, 11/07/2014, Palma). De igual manera, Atilio destaca la preexistencia indígena en el Paraguay: "hasta hoy la tierra es indígena [...] los indígenas son los primeros habitantes, los españoles casaron las mujeres y entonces blancos, los paraguayos son descendientes de indígenas" (Atilio, 25/07/2014, Palma). 
En sintonía con los relatos angaité recolectados por Villagra (2014) donde se recuerda la época previa a la guerra como aquella dónde no había paraguayos, los qom los declaran no "originales" de la zona ni propietarios de las tierras chaqueñas donde el conflicto bélico tuvo lugar. Tanto en las memorias de la guerra como en los discursos cotidianos en la comunidad, se marca una clara diferencia entre un "nosotros indígenas" y un "ellos paraguayos". Si bien se reconocen habitantes y ciudadanos del Paraguay, no se refieren a sí mismos como "paraguayos". Por el contrario, hay un reconocimiento general trans-pueblo de reconocerse como Nación Indígena. Es así que "[...] cuando estalló el conflicto, un tercio de la humanidad que circulaba en el espacio que correspondía a la zona de guerra existía fuera de las comunidades nacionales en pugna [...] decenas de miles de hombres y mujeres no eran ni paraguayos, ni bolivianos, ni miembros de ningún Estado" (Capdevila, 2010: 12).

Luego del conflicto, tanto los grupos participes de la guerra como aquellos que no intervinieron directamente se vieron replegados con el avance militar y progresivamente perdieron sus tierras con el desarrollo económico posterior. En el caso qom, las tierras que buscaron defender al asociarse con los paraguayos las terminaron perdiendo en manos de sus aliados una vez finalizada la contienda: “Antes, somos baqueanos, no había alambrados, todo terreno era. Después no hay más guerra y el Estado dice parcelar terreno cuando se acabó [la guerra], y los ancianos no saben. Parcelaron para ellos [el Estado] y los indígenas afuera" (Pablo, 13/7/2014, Palma). El énfasis discursivo depositado en la preexistencia indígena en el territorio abre la pregunta sobre una suerte de legitimación nacionalista que se desprende de los relatos. Tal legitimación validaría no sólo la participación en el conflicto (para defender "nuestras tierras") sino que también permite preguntarnos por la reelaboración de los testimonios de los caciques de guerra por las generaciones actuales con el fin de combatir la invisibilización e instalar el reclamo ${ }^{10}$.

La problemática del resarcimiento y reconocimiento por haber combatido dura hasta hoy: los paraguayos son reconocidos, recibieron pagos y pensiones por participar en la guerra mientras que los indígenas, no. La indignación, el descontento y la decepción rigen las memorias de la guerra junto al orgullo no sólo por haber participado sino por haber hecho que el Paraguay resulte vencedor:

Los paraguayos ganaron la batalla por los nativos, son baqueanos, ellos son los generales, sin ellos no ganan, cuando no hay agua, ellos dieron agua a los soldados, cuando se secó el monte, el indígena sabe, tomaron agua de hierba y ganaron, así contaron nuestros abuelos. Pero no hay nombre indígena [en el reconocimiento de la victoria] sólo paraguayos. Cuando hay hambre [en la batalla] no hay más galleta, los indígenas saben

\footnotetext{
${ }^{10}$ También debemos tener en cuenta que, como fue mencionado previamente, las experiencias indígenas de la guerra se instalan en una cronología que sobrepasa el momento exacto del conflicto (Capdevila, 2011); corresponden a regímenes de historicidad híbridos (Richard y Capdevila, 2016), por lo que las reelaboraciones de los testimonios de los padres y abuelos que lucharon en combate combinan la experiencia del grupo y del narrador con el conflicto en sí mismo y la situación actual.
} 
[dónde conseguir alimento] (Manuel, 11/07/2014, Palma).

La preocupación por la invisibilización y por la legitimación de la participación de sus padres y abuelos en el conflicto es concordante con la necesidad de instaurar el reclamo por la indemnización no recibida:

Anteriormente los toba en 1905 tenemos dos líderes: cacique de paz y cacique de guerra, actúan según si hay problema o no. Cuando empezó la guerra contra Bolivia en 1933 se fueron ahí con otros para ayudar a defender nuestros territorios pero los indígenas no aparecemos. 1870 la guerra de las 3, Argentina, Brasil, Uruguay. Pero ahí tampoco aparecemos. Los combatientes paraguayos cobraron y nosotros no. En la placita de la Villa [del Rosario] hay un letrero con los combatientes, pero ninguno indígena y la municipalidad dice que va arreglar pero no hacen (Herculano, 28/07/2014, Boquerón).

Luego de la progresiva pérdida de tierra, el grupo qom rosarino comenzó un camino errante y de pobreza, acentuado durante el desarrollo económico de los años 1950 y el posterior gobierno dictatorial de Alfredo Stroessner. Algunos de ellos, gracias a los hermanos Franciscanos, llegaron al área del Colegio Agrícola San Francisco de Asís en Cerrito. Otros, al decidir quedarse en Villa del Rosario, vivieron largos años en pequeñas carpas realizadas con bolsas de plástico trasladándose de un lado a otro dentro del distrito hasta que finalmente consiguieron los terrenos donde se ubican actualmente.

\section{Cuando pelear en el Chaco es hacer política en conjunto con el cosmos}

La perspectiva indígena del conflicto arriba detallada no sólo discute con la historiografía oficial y nos informa sobre la situación indígena al momento de la guerra, sino que permite indagar en las maneras indígenas de construir historia y hacer política con y a través del $\operatorname{cosmos}^{11}$ (y de las personas no-humanas que allí viven). Se trata de una "praxis política cósmica" 12 que da cuenta que "lo político no puede estar sólo ni exclusivamente ligado a los vínculos con los seres humanos" (López, 2013: 131).

Las personas no-humanas que pueblan el universo qom poseen una agencia (Tola, 2010, 2012; Tola y Suárez, 2013, 2016) que claramente se hace presente en la lucha por el Chaco durante la guerra a principios del siglo XX. Sean animales, sus dueños o los socios del chamán, en los relatos se esclarece cómo los poderes chamánicos y los no-humanos actuaron contra el ejército boliviano: ellos derribaron aviones, hicieron que bombas no exploten, que armas no disparen y que recursos naturales aparezcan.

${ }^{11}$ Entendido como un espacio social compartido y construido por las relaciones ente humanos y nohumanos.

${ }^{12}$ Dada la importancia de los no-humanos en el accionar qom durante la guerra y en la actualidad, y siguiendo la propuesta de López (2013) para grupos moqoit, la praxis política es una praxis política cósmica porque está atravesada por "la gestión de las relaciones con poderosos seres no-humanos" (López, 2013: 130). 
De igual manera, ellos facilitaron la obtención de información de las tropas enemigas y la comunicación a distancia: el canto chamánico y la comunicación a través de los animales permitió anticipar las acciones enemigas y actuar en consecuencia. El lugar de los no-humanos en la Guerra del Chaco deja entrever así el lugar de los no-humanos en la praxis política qom: chamanes, líderes y no-humanos defendieron en conjunto sus tierras. Peleando por el Chaco, hicieron política en él.

El contemplar el rol otorgado a los no-humanos en el quehacer político implica reconocer y tomar en serio "la presencia en la política de aquellos actores, que siendo otra cosa más que humanos [being other than human], las disciplinas dominantes asignaron a la esfera de la naturaleza (donde debían ser conocidos por la ciencia) o a los campos metafísicos y simbólicos del conocimiento" (De La Cadena, 2010: 336, traducción nuestra).

De esta manera, la perspectiva indígena del conflicto se encuentra atravesada por una cosmopolítica que permite problematizar la "política" tal como la conocemos y contemplar que los no-humanos pueden derribar aviones del ejército boliviano y hacer vencedor al Paraguay en un conflicto bélico supuestamente internacional.

\section{La Guerra del Chaco a ambas márgenes del Pilcomayo}

Como ha sido establecido, la Guerra del Chaco tuvo efectos variados sobre los pueblos chaqueños (Córdoba y Braunstein, 2008; Villagra, 2014; Rabinovich, 2015; Córdoba, 2016), inclusive sobre distintas parcialidades de un mismo pueblo indígena. Si bien la modificación de los patrones de asentamiento y la pérdida territorial es el denominador común, las experiencias y memorias qom sobre la guerra aquí presentadas resuenan en contraposición a las memorias de las comunidades toba del oeste de la provincia de Formosa (antiguos habitantes de "la banda") (Gordillo, 2005, 2010b; Gordillo y Leguizamón, 2002; Córdoba y Braunstein, 2010; Córdoba, 2016).

A diferencia de las campañas de ocupación militar en Argentina, la Guerra del Chaco en Paraguay no fue planteada como una guerra de conquista de un Estado vs. comunidades indígenas, sino una guerra del ejército paraguayo vs. ejército boliviano. La guerra desde el Paraguay fue así - oficialmente y en teoría - una guerra "justa" declarada en defensa de la patria, en nombre de la soberanía nacional (Capdevila, 2010) frente a un enemigo extranjero. En los diferentes contextos políticos y estatales de ambos países, el vínculo indígena con la presencia militar a un lado y otro del Pilcomayo es recordado de maneras totalmente opuestas. Los grupos toba-pilagá que antiguamente habitaban a ambas márgenes del río vieron estallar la guerra frente a sus comunidades y, aunque al mantenerse asentados sobre la orilla argentina del río permanecieron en zona neutral, al cruzar "la banda" para cazar o hacerse de los descartes de guerra abandonados por los ejércitos fueron víctimas de disparos y ataques (Gordillo 2005, 2010b; Córdoba y Braunstein, 2008; Córdoba, 2016). Esto afectó la "subjetividad" de los grupos e hizo que muchos animales y "seres" se refugiaran en el territorio de "la banda", el cual fue abandonado con el tiempo debido a la ocupación sistemática de las tropas paraguayas (Gordillo y Leguizamón, 2002). A raíz de la guerra, dicho territorio “dejó de 
ser conceptualizado como propio y pasó a ser percibido como una región ajena, más allá de la frontera establecida por el río, en el cual se podía incursionar pero no establecerse definitivamente" (Córdoba y Braunstein, 2008: 136).

Mientras para los toba del oeste el conflicto implicó abandonar las tierras ubicadas al norte del río Pilcomayo y movilizarse hacia el sur, para los pilagá no significó mayores consecuencias ya que ocupaban el lado argentino del río (Córdoba y Braunstein, 2008; Córdoba, 2016). Si bien dichos grupos no se vieron directamente implicados en el campo de batalla, "el conflicto reconfiguró la geografía política indígena” (Gómez, 2010: 92). A diferencia de los toba-pilagá, que no reconocían al río como una frontera, los pilagá "habían desarrollado un modo de identidad que incorporaba la categoría nacional del Estado y el límite jurisdiccional" (Córdoba y Braunstein, 2008: 129) lo cual explica "su condición de «indígenas argentinos»" y su función de "guardianes" de la frontera (Córdoba y Braunstein, 2008: 129). Por su lado, los qom rosarinos intentaron ser guardianes del territorio que de todas maneras terminarían perdiendo a manos de sus compañeros de lucha.

Como hemos visto, en los testimonios rosarinos se hacen presente la necesidad de legitimación y reconocimiento, de combatir la invisibilización y de reclamar indemnización. Tal problemática contemporánea se arraiga en el hecho de que la contienda fue un evento que marcó críticamente su historia, un punto de importancia en la desterritorialización sufrida, a diferencia de los toba-pilagá entre quienes el "punto de inflexión crítico (...) es [fue] la instalación de los misioneros anglicanos" (Córdoba y Braunstein, 2008: 139). El contexto geográfico y socio-político en que se encontraban ambos grupos sienta las bases para esta variabilidad de experiencias y de relevancia dada a la contienda: los grupos que terminaron por instalarse al sur del Pilcomayo ya habían sufrido el avance militar argentino cuando la guerra, la milicia y la conquista estatal avanzan sobre el territorio indígena en el Paraguay a comienzos del siglo XX. Mientras entre los qom rosarinos la presencia de los religiosos no se torna relevante en su historia oral hasta el contacto con los Hermanos Franciscanos durante la segunda mitad del siglo $\mathrm{XX}^{13}$, entre los toba-pilagá los misioneros ocupan un papel de suma importancia en su relato histórico (Córdoba y Braunstein, 2008; Córdoba, 2016). Las misiones no sólo los protegieron de los criollos y de los atropellos del ejército, primero argentino y luego paraguayo cuando comenzó la Guerra del Chaco (Córdoba, 2016), sino que con su llegada comenzaron "a incorporarse lentamente en un contexto nacional más amplio" (Córdoba y Braunstein, 2008: 140). Para el momento de la contienda, por ejemplo, los toba-pilagá recuerdan que "fueron los misioneros quienes colocaron «... una sábana en el techo de la misión para mostrar a los aviones que había una misión ahí, que no podían disparar»" (Córdoba y Braunstein, 2008: 141). Esa incorporación a un contexto nacional más amplio, en el caso de los qom rosarinos se concreta a raíz de la guerra y sin la intermediación de los misioneros.

\footnotetext{
${ }^{13}$ Momento en que la mayoría de las familias rosarinas, dada la falta de tierra propia en Villa del Rosario, se mudaron a las tierras del Colegio Agrícola San Francisco de Asís en Cerrito que los religiosos dispusieron para la comunidad toba (allí ya vivían los toba cerriteños).
} 
De esta manera, mientras desdeArgentina los grupos toba y pilagá experimentaron una guerra completamente ajena ya que "Nadie de acá peleó esa guerra... la gente toba lo veía nomás, andaba, miraba... cuando peleaban se miraba nomás..." (relato de campo en Córdoba y Braunstein, 2008: 137), en Paraguay líderes y chamanes toba se introdujeron en el corazón mismo del conflicto de la mano del ejército. Si la historia oral toba-pilagá es "prodigia en episodios que ilustran el temor (...) frente al accionar violento de los militares" (Córdoba y Braunstein, 2008: 139) y muestra que inclusive finalizada la contienda continuaron los enfrentamientos con las tropas paraguayas ya que seguían "cruzando el río para cazar o para recolectar armas" (Córdoba y Braunstein, 2008: 145), las narrativas orales qom rosarinas construyen una experiencia del conflicto basada en el accionar guerrero de sus padres y abuelos que en lugar de enfrentarse a los paraguayos, de la mano de los no-humanos pelearon junto a ellos.

\section{Notas finales}

Las memorias presentadas a lo largo de este artículo permitieron abordar la situación qom al momento de la Guerra del Chaco y su perspectiva del conflicto. Por un lado, retomar los datos recolectados para otros grupos del Chaco paraguayo permitió ponerlos en diálogo con los relatos qom rosarinos, desconocidos hasta el momento para el área paraguaya. Las narrativas en cuestión dan cuenta de un tipo de experiencia de la guerra no necesariamente basada en la violencia y el avallasamiento del ejército paraguayo, sino una experiencia de lucha y combate mano a mano con el mismo en pos de defender un territorio considerado propio frente a un nuevo invasor, el Estado boliviano. En las memorias qom de la guerra se ve una intencionalidad manifiesta de recalcar continuamente el hecho de que el Paraguay venció gracias a la participación indígena, especialmente de los chamanes. Los relatos destacan que si no fuera por el accionar chamánico, el conocimiento del terreno y su capacidad de ser baqueanos, la guerra hubiera tenido otro desenlace: los soldados paraguayos hubieran muerto de sed, los aviones bolivianos hubieran funcionado, sus bombas explotado y el Paraguay finalmente no hubiera vencido. Asimismo, los relatos ubican al conflicto bélico como un importante marcador temporal en la memoria histórica qom rosarina: previo al mismo, no había una fuerte presencia estatal en el área, los paraguayos no son "originarios" de la misma, es con la finalización de la guerra que el Estado entra a parcelar la tierra, ocuparla, venderla, y a desplazar a aquellos que la habitaban previamente. En función de esta situación, los relatos también enfatizan la necesidad de los qom de ser reconocidos por su participación en la contienda, de que los nombres indígenas aparezcan junto a los de los soldados paraguayos en los monumentos y que el pueblo qom sea igualmente resarcido por su involucramiento. En el caso de las narrativas qom rosarinas, asociada a la Guerra del Chaco se evidencia un tipo de violencia estatal que radica en la desterritorialización, en la gubernamentalidad que surge en la posguerra y en la invisibilización sufrida. Entre los qom rosarinos, la total y prolongada invisibilización de su participación en la guerra sigue viva hoy día y en su momento no hizo más que hundir cualquier posibilidad de reclamo. 
Por otro lado, abordar las memorias qom de la Guerra del Chaco nos informa sobre maneras de pelear y hacer política en conjunto con personas no-humanas. No sólo los chamanes fueron a la guerra con el ejército paraguayo sino también los no-humanos a ellos asociados. La praxis política qom es así una cosmopolítica que permite visibilizar la participación indígena en la contienda al mismo tiempo que dar cuenta de una manera de hacer política y construir historia en conjunto con el cosmos. De igual manera, el rol de los chamanes en la guerra permite abordar el chamanismo en una temporalidad amplia contemplando los procesos socio-históricos atravesados por la comunidad: del conflicto hacia atrás, en vínculo a las antiguas incursiones y la importancia de los guerreros; hacia el presente, en vínculo con las maneras actuales en que los chamanes también pelean por medio de sus lavanec.

Por último, indagar en las memorias qom rosarinas nos permite comparar y conocer dos experiencias opuestas de grupos de un mismo pueblo indígena en torno al mismo conflicto. El breve recorrido por las trayectorias y movilidades socio históricas del pueblo toba esboza cómo fueron surgiendo distintas parcialidades. Los movimientos desde el río Pilcomayo hacia el río Paraguay en conjunto con los procesos de fusión y fisión constatan la posibilidad de que diferentes grupos quedaran incorporados a dos Estado nación distintos y habilitan la discusión de una noción de frontera estática, inexistente para los grupos en cuestión. Los marcos estatales en que acabaron insertos determinaron de esta manera la experiencia de la guerra de aquellos toba que quedaron del lado argentino del río Pilcomayo y los que se habían instalado al norte del mismo en territorio paraguayo. Si bien para ambos implicó el desplazamiento, mientras para los toba argentinos la Guerra del Chaco fue una guerra ajena, aquellos que habitan en el Paraguay pelearon en el corazón de la misma.

\section{Referencias bibliográficas}

\section{Fuentes}

"Breve historia de la comunidad indígena toba qom", Anexo al documento legal presentado para el reconocimiento de la personería jurídica en 1988. Documento realizado, firmado y presentado por Servicios Profesionales Socio-Antropológicos y Jurídicos frente al Instituto Paraguayo del Indígena el 25 de abril de 1988, Asunción.

Plan de Desarrollo de la Comunidad Indígena Toba Qom "Bagia ga loge lacheg (aldeas Palma y Boquerón) - Río Cuarepoti”. Año 2012. Proyecto de desarrollo rural sostenible (PRODERS), Ministerio de Agricultura y Ganadería, República del Paraguay. 


\section{Bibliografia}

Arnott, J. 1934. "Los toba-pilagá del Chaco y sus guerras". En: Revista Geográfica Americana,

Vol. 1 No. 7, Buenos Aires, Sociedad Geográfica Americana. pp. 491-501.

Barbosa, P. y Richard, N. 2010. "La danza del cautivo. Figuras nivaclés de la ocupación del Chaco". En: L. Capdevila, I. Combès, N. Richard y P. Barbosa (eds.) Los hombres transparentes. Indigenas y militares en la Guerra del Chaco (19321935), Instituto de Misionología, pp. 121-176.

Bejarano, R. C. 1984. Fortines Paraguayos y Bolivianos, 1905-1932, Asunción.

Bossert, F.; Combès, I. y Villar, D. 2008. "La Guerra del Chaco entre los Chané e isoseños del Chaco". En: Richard, N. (ed.). Mala Guerra. Los indígenas en la guerra del Chaco (1932-1935), Servilibro, Museo del Barro, Colibris, pp. 203-232.

Capdevila, L. 2010. "La guerra del Chaco tierra adentro. Desarticulando la representación de un conflicto internacional". En: L. Capdevila, I. Combès, N. Richard y P. Barbosa (eds.). Los hombres transparentes. Indígenas y militares en la Guerra del Chaco (1932-1935), Instituto de Misionología, pp. 11-32.

Capdevila, L. 2011. "La guerra del Chaco en la encrucijada de las memorias indígenas y de la historia militar. La polifonía de una situación colonial". En: J.M. Casals y T. Whigham (eds.). Paraguay en la historia, la literatura y la memoria, Universidad de Montevideo/Tiempo de Historia, pp. 267-280.

Capdevila, L. 2013. «Colonialismos nacionales en acción: Experiencias militares en Chaco boreal en vísperas de la guerra, 1920/1930». En: Nuevo Mundo Mundos Nuevos [En Línea], Debates, Puesto en línea el 15 de febrero de 2015, consultado el 10 de junio de 2016. URL: https://nuevomundo.revues.org/65031; DOI: 10.4000/nuevomundo.65031.

Capdevila, L. 2015. «La Guerra de la Triple Alianza (1865-1870) y la Guerra del Chaco (1932-1935). Dos guerras internacionales en un marco colonial», Corpus [En línea], Puesto en línea el 29 junio de 2015, consultado el 10 de junio de 2016. URL: http://corpusarchivos.revues.org/1399; DOI: 10.4000/corpusarchivos.1399.

Capdevila, L.; Combès, I.; Richard, N. y Barbosa, P. (eds.). 2010. Los hombres transparentes. Indigenas y militares en la guerra del Chaco (1932-1935), Cochabamba, Instituto de Misionología.

Capdevila, L. y Richard, N. 2016. «Des voix pour partager le passé. Mémoires et narrations amérindiennes de la guerre du Chaco (1932-1935)". En: C. Heimberg, F. Rousseau y Y. Thanassekos (dir.), Témoins et témoignages, figures et objets du XXe siècle, L' Harmattan, pp. 293-305.

Comaroff, J. y J. Comaroff. 2009. Violencia y ley en la poscolonia: una reflexión sobre las complicidades Norte-Sur, Buenos Aires, Katz Editores, Barcelona, Centro de Cultura Contemporánea de Barcelona.

Combès, I. 2010. "El coronel Ayoroa y los indios del lugar". En: L. Capdevila, I. Combès, N. Richard y P. Barbosa (eds.) Los hombres transparentes. Indigenas y militares en la Guerra del Chaco (1932-1935), Instituto de Misionología, pp. 33-82. 
Cordeu, E. 2008. "La memoria ishir (chamacoco) de la Guerra del Chaco". En: Richard, N. (ed.). Mala Guerra. Los indigenas en la guerra del Chaco (1932-1935), ServiLibro, Museo del Barro, CoLibris, pp. 251-290.

Córdoba, L. 2016. «Mission en temps de guerre: Alfred Métraux dans le Pilcomayo », Journal de la société des américanistes [En ligne], 102-2, Puesto en línea el 26 de enero de 2017, Consultado el 22 de abril de 2017.. URL: http://jsa.revues. org/14806; DOI: 10.4000/jsa.14806.

Córdoba, L. y Braunstein, J. 2008. "Cañonazos en "La Banda". La Guerra del Chaco y los indigenas del Pilcomayo medio". En: Richard, N. (ed.). Mala Guerra. Los indigenas en la guerra del Chaco (1932-1935), ServiLibro, Museo del Barro, CoLibris, pp. 125-148.

De La Cadena, M. 2010. «Indigenous cosmopolitics in the Andes: Conceptual Reflections beyond "Politics"». En: Cultural Anthropology [En línea], Puesto en línea el 15 de abril de 2010, Consultado el 6 de julio de 2013. URL: http:// onlinelibrary.wiley.com/wol1/doi/10.1111/j.1548-1360.2010.01061.x/full; DOI: 10.1111/j.1548-1360.2010.01061.x

Fabre, A. 2006. "Los pueblos del Gran Chaco y sus lenguas, tercera parte: los guaycurú". En: Suplemento Antropológico, Vol. 2, Asunción, Centro de Estudios Antropológicos, Universidad Católica. pp. 7-132.

Foucault, M. 1991 "La gubernamentalidad". En: Espacios de poder, La Piqueta, pp. 9-26.

Fritz, M. 2008. "Indígenas y la Guerra del Chaco. El impacto de lo indecible". En: Richard, N. (ed.). Mala Guerra. Los indígenas en la guerra del Chaco (19321935), ServiLibro, Museo del Barro, CoLibris, pp. 149-169.

Gómez, C. 2010. "Los tobas del oeste formoseño y los misioneros de la South American Missionary Society". En: Archivo, Vol. 8, Buenos Aires, Centro de Investigaciones en Antropología Filosófica y Cultural de la Asociación Argentina de CulturaConicet. pp. $81-117$.

Gordillo, G. 2005. Nosotros vamos a estar acá para siempre. Historias Tobas, Buenos Aires, Biblos.

Gordillo, G. 2010a. «Historias de los bosques que alguna vez fueron pastizales: la producción de la naturaleza en la frontera argentino paraguaya». En: Población \&Sociedad [En línea], Puesto en línea en febrero de 2011, consultado el 3 de mayo de 2014. URL: http://www.poblacionysociedad.org.ar/archivos/17/P\&SV17-Gordillo.pdf; ISSN-L 03283445

Gordillo, G. 2010b. Lugares de diablos. Tensiones del espacio y la memoria, Buenos Aires, Prometeo.

Gordillo, G. y Leguizamón, J. M. 2002. El río y la frontera. Movilizaciones aborígenes, obras públicas y MERCOSUR en el Pilcomayo, Buenos Aires, Biblos.

Iñigo Carrera, N. 1983. La colonización del Chaco, Buenos Aires, Centro Editor de América Latina. 
Kalisch, H. y Unruh, E. 2008. "Salvación ¿rendición? Los enlhet y la Guerra del Chaco". En: Richard, N. (ed.). Mala Guerra. Los indigenas en la guerra del Chaco (19321935), ServiLibro, Museo del Barro, CoLibris, pp. 99-124.

Kersten, L. 1968[1904]. Las tribus indígenas del Gran Chaco hasta fines del siglo XVIII, Resistecia, Universidad Nacional del Nordeste.

López, A. M. 2013. "Las texturas del cielo. Una aproximación a las topologías moqoit del poder”. En: F. Tola, C. Medrano y L. Cardín (eds.) Gran Chaco. Ontologías, poder, afectividad, Asociación Civil Rumbo Sur, pp. 103-131.

Métraux, A. 1933. "La guerra primitiva en el Chaco". En: La Prensa, 08/01/1933, Buenos Aires.

Métraux, A. 1946. Myth of the Toba and Pilagá Indians of the Gran Chaco, Philadelphia, American Folklore Society.

Métraux, A. 1963. "Ethnography of the Chaco". En: J. Stewart (ed.) Handbook of South American Indians, Vol. 1, Smithsonian Institution, Washington, pp. 196-370.

Nordenskiöld, E. 1912. La vie des Indiens dans le Chaco (Amérique du Sud) (18771932).

Querejazu Calvo, R. 1975. Masamaclay: historia política diplomática y militar de la Guerra del Chaco, La Paz, Los Amigos del Libro.

Querejazu Calvo, R. 1990. Historia de la Guerra del Chaco, La Paz, Juventud.

Rabinovich, A., Richard, N., Villar, D., Nielsen, A. y Capdevila, L. 2015. «Discusión», En: Corpus [En línea], Puesto en línea el 30 junio 2015, consultado el 10 de junio de 2016. URL: http://corpusarchivos.revues.org/1401; DOI: 10.4000/ corpusarchivos. 1401

Richard, N. ; Capdevila, L. y Boidin, C. (eds.). 2007. Les Guerres du Paraguay aux XIXe et XXe siècles, París, CoLibris.

Richard, N. 2008. Mala Guerra. Los indigenas en la guerra del Chaco (1932-35), Asunción-París, ServiLibro, Museo del Barro, CoLibris.

Susnik, B. 1981. Etnohistoria de los Chaqueños 1650-1910. Los aborígenes del Paraguay,Asunción, Museo Etnográfico Andrés Barbero, Vol. 3/1.

Susnik, B. 1986-87. Los aborígenes del Paraguay, Asunción, Museo Etnográfico Andrés Barbero, Vol. 7/1: Lenguas chaqueñas.

Susnik, B. 1989. "Etnohistoria del Paraguay". En: América Indígena, Vol. 49 No. 3. pp. 431-490.

Tola, F. 2010. «Maîtres, chamanes et amants», Ateliers du LESC [En línea], Puesto en línea el 27 septiembre de 2010, consultado el 17 de agosto de 2013. URL: http:// ateliers.revues.org/8538; DOI: 10.4000/ateliers.8538

Tola, F. 2012. Yo no estoy solo en mi cuerpo. Cuerpos-personas múltiples entre los tobas del Chaco Argentino, Buenos Aires, Biblos.

Tola, F. y Suárez, V. 2013. "Diálogo sobre los existentes de un entorno superpoblado en el contexto de la marisca y la reivindicación política del territorio". En: F. Tola, C. Medrano y L. Cardín (eds.) Gran Chaco. Ontologías, poder, afectividad, Asociación Civil Rumbo Sur/ethnographica, pp. 45-76. 
Tola, F. y Suárez, V. 2016. El teatro chaqueño de las crueldades, memorias qom de la violencia y el poder, Buenos Aires, Asociación Civil Rumbo Sur - Instituto de Investigaciones Geohistóricas.

Vázquez, F. 2012. "El Estado paraguayo en el espacio: centralización y desafíos de gestión territorial inteligente". En: Dalla-Corte Caballero, G. (coord.) Estado, Nación e Historia en el Bicentenario de la Independencia del Paraguay, Asunción, Intercontinental Editora, pp. 153-170.

Villagra Carrón, R. 2014. Meike makha valayo. No habían paraguayos. Reflexiones etnográficas en torno a los angaité del Chaco, Asunción, AECID, CEADUC, Tierra Viva.

Wright, P. 2008. Ser-en-el-sueño. Crónicas de historia y vida toba, Buenos Aires, Biblos. Zanardini, J. 2011. Los pueblos indígenas del Paraguay, Asunción, El Lector. 
